\title{
Altın Vadeli İşlem Sözleşmelerinin Muhasebeleştirilmesi ${ }^{*}$
}

\author{
Mustafa KILLI ** \\ Samet EVCI $\dot{I}^{* * *}$
}

\section{ÖZET}

Son zamanlarda türev finansal araçların kullanımı ülkemizde giderek artmaktadır. Türev piyasalarda işlem gören finansal araçlardan biri de vadeli işlem sözleşmeleridir. Vadeli işlem sözleşmeleri, sözleşmenin taraflarına, standartlaştırılmış miktar ve kalitedeki bir mal, klymeti veya finansal göstergeyi, belirlenen ileri bir tarihte, bugünden üzerinde anlaşılan fiyattan alma veya satma yükümlülüğ̈̈ getiren sözleşmelerdir. Riskten korunmak isteyen yatırımcilar, spekülatörler ve arbitrajcllar vadeli işlem piyasalarında işlem yapabilmektedirler. Vadeli işlem piyasalarında pay senedi, borsa endeksi, döviz, altın, emtia, enerji gibi çeşitli dayanak varlıklara bağlı vadeli işlem sözleşmeleri işlem görmektedir.

Bu çalışmada, vadeli işlem sözleşmeleri çeşitli yönleriyle açılklandıktan sonra TMS 39 Finansal Araçlar: Muhasebeleştirme ve Ölçme Standardı kapsaminda Borsa İstanbul'da Vadeli İşlem ve Opsiyon Piyasası'nda işlem görmekte olan Altın Vadeli İşlem Sözleşmelerinin muhasebeleştirilmesine yönelik uygulama örneklerine yer verilmiştir.

Anahtar Kelimeler: Türev Araçlar, Vadeli İşlem Sözleşmeleri, TMS 39.

JEL Sinıflandirması: M40, M41.

\section{Recognition of Gold Futures Contracts}

\section{ABSTRACT}

The use of derivative financial instruments has been recently increasing in our country. One of the financial instruments traded in derivative markets is futures contracts. A futures contract is a standardized contract between two parties obligating them to buy or sell a predetermined quantity of a specified underlying asset of predetermined features at a predetermined price in a certain maturity. Investors who want to protect themselves from risk, speculators and arbitrageurs can make transactions in the futures market. Futures contracts on depending various underlying assets such as stock, indexes, foreign exchange, gold, commodities and energy are traded in futures markets.

In this study, at first explaining various aspects of futures contracts then practises relating to recognition of Gold Futures Contracts that trading in Derivatives Market in Borsa Istanbul within the framework of TAS 39 Financial Instruments: Recognition and Measurement Standard are given.

Keywords: Derivatives, Futures Contracts, TAS 39.

Jel Classification: M40, M41.

\footnotetext{
* Bu çalışma 22-23 Eylül 2016 tarihlerinde Uşak’ta düzenlenen 1.Uluslararası Gelecek İçin Bilimsel İşbirliği Konferansinda (1.International Conference on Scientific Cooperation for Future) bildiri olarak sunulmuş ve daha sonra geliştirilerek makale haline getirilmiştir.

** Yrd.Doç.Dr. Mustafa Kıllı, Osmaniye Korkut Ata Üniversitesi, İktisadi ve İdari Bilimler Fakültesi, mkilli@osmaniye.edu.tr

${ }^{* * *}$ Yrd.Doç.Dr. Samet Evci, Osmaniye Korkut Ata Üniversitesi, İktisadi ve İdari Bilimler Fakültesi, sametevci@osmaniye.edu.tr
} 


\section{GíRiş}

Altın, finansal piyasalarda yatırım aracı olarak; kuyumculuk, elektronik ve sağlık sektörü gibi birçok endüstriyel alanda hammadde olarak yaygın bir kullanım alanına sahiptir. $\mathrm{Bu}$ nedenle altın fiyatlarındaki oynaklık altın yatırımcısının ve işletmelerin piyasa riskine maruz kalmasına neden olmaktadır. Maruz kalınan riski yönetmek amacıyla kullanılan araçlardan biri de türev finansal araçlardır. Türev araçlar, fiyatları bir başka ürünün fiyatına bağlı olan ürünler ya da vade sonundaki değeri sözleşmeye konu olan varlığın fiyatı tarafindan belirlenen finansal varlık olarak tanımlanabilir (Çonkar ve Ata, 2002: 5). Bu kapsamda kullanılan araçlar arasında forward, vadeli işlem (futures), opsiyon ve swap sözleşmeleri yer almaktadır. Bu araçlar arasından vadeli işlem sözleşmeleri, standart süre ve tutarı içeren, organize borsalarda işlem gören ve günlük dengeleme prosedürüne bağlı olan bir anlaşmadır (Chambers, 2012:6). Vadeli işlem sözleşmeleri spekülasyon, arbitraj ve riskten korunma amaçlı olarak yaygın şekilde kullanılmaktadır. Bu durum vadeli işlem sözleşmelerin nasıl muhasebeleştirileceği ve finansal tablolarda nasıl raporlanacağı sorununu da getirmiştir. Türev finansal araçların muhasebeleştirilmesi ve ölçülmesi konusunda düzenlemeler getiren Türkiye Muhasebe Standardı (TMS) 39 Finansal Araçlar: Muhasebeleştirme ve Ölçme standardı, finansal araçların tanımları, sınıflandırılması, kayda alma, değerleme, raporlama ve kayıttan çıkarma yöntemlerini kapsamaktadır.

Literatür incelendiğinde altın vadeli işlem sözleşmelerinin muhasebeleştirilmesini konu alan çalışmaya rastlanmamıştır. Bu çalışmanın amacı, Borsa İstanbul (BİST) Vadeli İşlem ve Opsiyon Piyasası'nda (VİOP) işlem gören vadeli işlem sözleşmelerinin türleri, özellikleri ve işleyişini incelemek ve TMS 39 Finansal Araçlar: Muhasebeleştirme ve Ölçme standardı çerçevesinde muhasebeleştirilme ilkelerini örnek uygulamalar ile açıklamaktır.

\section{VADELİ İŞLEM SÖZLEŞMELERİ}

Vadeli işlem sözleşmeleri ya da futures sözleşmeleri, sözleşmenin taraflarına belirlenen gelecekteki bir tarihte, üzerinde anlaşılan fiyattan, standartlaştırılmış miktar ve kalitedeki bir malı, kıymeti veya finansal göstergeyi alma veya satma yükümlülüğü getiren sözleşmelerdir (Karatepe, 2000: 11). Genel olarak vadeli işlem sözleşmesinde taraflar, alıc1, satıcı, vadeli işlem borsası, takas kurumu ve aracı kurumlardan oluşmaktadır. Alıcı, vadeli işlem sözleşmesini satın alan yani sözleşmede uzun pozisyon alan taraf iken satıcı, sözleşmeyi yazan yani kısa pozisyon alan taraftır (Bouchentouf, 2007:138). Vadeli işlem sözleşmesinde uzun pozisyon almış bir yatırımcı gelecekte belli bir tarihte, belirlenen fiyattan, belirlenen miktarda malı, anlaşmanın karşı tarafından satın almak zorundadır. Kısa pozisyon almış yatırımcı ise gelecekte belli bir tarihte, belirlenen fiyattan, belirlenen miktardaki malı anlaşmanın karşı tarafında yer alan kişiye yani uzun pozisyon almış kişiye teslim etmek zorundadır (Doğukanl1, 2008: 137). Vadeli işlem piyasasında uzun pozisyon alan yatırımcı fiyatların yükseleceği beklentisi içerisinde iken kısa pozisyon alan yatırımcı fiyatların düşeceği beklentisi içerisindedir (Bouchentouf, 2007: 138). Bu piyasaya konu olan 
sözleşmelerin büyüklüğü, sözleşmeye konu olan dayanak varlığın niteliği, kalitesi, işlem gördüğü para birimi, pozisyon ve fiyat limitleri gibi sözleşmeye ilişkin tüm hükümler vadeli işlem borsası tarafından belirlenmekte ve standart hale getirilmektedir. Vadeli işlem sözleşmelerinde diğer bir taraf ise takas kurumudur. Takas kurumu, vadeli işlem piyasasında yapılan tüm işlemlerde alıcı ve satıcının muhatap olduğu ve tarafların sözleşmeden doğan yükümlülüklerini yerine getirmemesinden kaynaklanan tüm riskleri üstlenen kurumdur (Frush, 2008: 227).

Vadeli işlem sözleşmeleri herhangi bir finansal varlık (hisse senedi, tahvil, bono, hisse senedi endeksi, dolar, euro gibi) üzerine düzenlenebileceği gibi emtialar (altın, bakır, platin, pamuk, pirinç, buğday) üzerine de düzenlenebilmektedir. Ülkemizde vadeli işlem sözleşmeleri BİST bünyesinde yer alan VİOP'ta işlem görmektedir. Bu piyasada işlem gören sözleşmeler, pay, endeks, döviz, kıymetli madenler, emtia, enerji, yabancı endeks, metal, borsa yatırım fonu ve gecelik repo vadeli işlem sözleşmeleri olarak sınıflandırılmaktadır. Sözleşmelere konu olan dayanak varlıklar, pay vadeli işlem sözleşmelerinde BİST pay piyasasında işlem gören hisse senetlerinden, endeks vadeli işlem sözleşmelerinde BİST 30 endeks değerinin 1000'e bölünmüşs şeklinden, döviz vadeli işlem sözleşmelerinde TL/ABD doları, TL/Euro ve Euro/ABD doları çapraz kurlarından, kıymetli maden vadeli işlem sözleşmelerinde ise saf altından oluşmaktadır. Emtia vadeli işlem sözleşmesi olarak Ege pamuk, Anadolu kırmızı buğday ve makarnalık buğday vadeli işlem sözleşmeleri işlem görmekte iken enerji vadeli işlem sözleşmesi altında elektrik, yabancı endeks altında SASX 10 Endeksi, metal sözleşmesi altında çelik hurda, borsa yatırım fonu altında FBİST borsa yatırım fonu ve gecelik repo altında ise aylık ve üç aylık gecelik repo oranı vadeli işlem sözleşmeleri işlem görmektedir (http://www.borsaistanbul.com/sss/vadeli-islem-ve-opsiyonpiyasasi-viop).

\section{VADELİ IŞLEM SÖZLEŞMELERINDE KARIN VE ZARARIN HESAPLANMASI}

Vadeli işlem piyasasında işlem yapmak isteyen yatırımcının öncelikli olarak takas kurumu tarafından belirlenen ve pozisyon alınacak sözleşmeye göre farklılık gösteren başlangıç teminatını yatırması gerekmektedir. Yatırımcının teminat hesabı, vadeli işlem piyasasında aldığı kısa veya uzun pozisyona göre uzlaşma fiyatı esas alınarak her gün kontrol edilmektedir. Uzlaşma fiyatı, günlük kar-zararın hesaplanmasında ve teminat gereksiniminin belirlenmesinde kullanılan fiyattır. Uzlaşma fiyatı genellikle seans sona ermeden önce işlem gören sözleşmelerin fiyatları esas alınarak hesaplanmakta ve borsa tarafından ilan edilmektedir (Hull, 2012: 35). Bir vadeli işlem sözleşmesinde uzun pozisyon alan yatırımcı için kar, pozisyon aldığı vadeli işlem sözleşmenin piyasa fiyatının artması, zarar ise vadeli işlem sözleşmesinin fiyatının düşmesi durumunda ortaya çıkmaktadır. Kısa pozisyon alan bir yatırımcı ise vadeli sözleşmenin fiyatı arttığında zarar, azaldığında ise kar etmektedir. Yatırımcının zarar etmesi ve teminat hesabının belli bir seviyenin altına gerilemesi 
durumunda Takas Kurumu teminat çağrısında bulunur. Teminat hesabının düşebileceği bu alt sınır sürdürme teminatı seviyesidir. Sürdürme teminatı seviyesi genellikle başlangıç teminatı seviyesinin \%75'i olarak belirlenmektedir (VOB Türev Araçlar Lisanslama Rehberi, 2006: 21-44). Alıcı ya da satıcının gün sonunda zarar etmesi ve başlangıç teminatının sürdürme teminatının altına düşmesi durumunda takas kurumu yatırımcıdan teminatın başlangıç seviyesine çıkartılması için ek fon talep eder. Buna teminat tamamlama çağrısı adı verilir. Eğer yatırımcı hesabını istenen seviyeye çıkartamıyorsa hesap kapatılmaktadır. Vadeli işlem sözleşmelerinde pozisyon, sözleşmeye konu olan varlığın fiziki teslimiyle, nakdi ödemeyle veya vadeli işlem borsasında sözleşmeye uygun ters bir işlemle kapatılmaktadır. (Ceylan ve Korkmaz, 2008: 596).

Vadeli işlem sözleşmelerinde pozisyonun kapatılması durumunda toplam kar-zarar tutarı, günlük hesaplaşmalar sonucunda belirlenen geçici kar-zararların toplanması suretiyle hesaplanabileceği gibi aşağıdaki formül kullanılarak da hesaplanabilmektedir (VOB Teminatlandırma ve Diğer Risk Yönetimi Esasları, 2005: 21)

Uzun pozisyon alınması durumunda;

Kar/Zarar=(Uzlaşma Fiyatı-İşlem Fiyat1)*Sözleşme Büyüklüğü*Pozisyon Adedi

Kısa pozisyon alınması durumunda;

Kar/Zarar=(İşlem Fiyatı-Uzlaşma Fiyatı)*Sözleşme Büyüklüğü*Pozisyon Adedi

Günlük hesaplaşma durumunda yatıımcının geçici kar-zararını hesaplamak için yukarıdaki eşitlikte uzlaşma fiyatı olarak gün sonunda belirlenen uzlaşma fiyatı esas alınırken, pozisyon kapatılması durumunda kesin kar-zararı hesaplamak için son işlem günü uzlaşma fiyatı yani vade sonu uzlaşma fiyatı dikkate alınmaktadır.

\section{VADELİ İSLEM SÖZLESSMELERINIIN MUHASEBELEȘTİRILMESI}

Finansal araçların muhasebeleştirilmesi ve ölçülmesine ilişkin düzenlemeler getiren "TMS 39 Finansal Araçlar: Muhasebeleştirme ve Ölçme" Standardı 31/12/2005 tarihinden sonra başlayan hesap dönemleri için uygulanmak üzere ilk defa 03/11/2006 tarih ve 26335 sayılı Resmi Gazetede yayımlanmıştır. Standart, finansal varlıkların, finansal borçların ve finansal olmayan kalemlerin alım satımına ilişkin düzenlenen sözleşmelerin muhasebeleştirme ve ölçülmesine yönelik ilkeleri belirlemek amacını taşımaktadır.

TMS 39 Finansal Araçlar: Muhasebeleştirme ve Ölçme standardına göre; gerçeğe uygun değerle ölçülen bir finansal varlıktan ya da finansal borçtan kaynaklanan kazanç veya kayıplar kâr veya zararda muhasebeleştirilmelidir. Buna göre, altın vadeli işlem sözleşmelerinden elde edilen kazanç ve kayıpların ait oldukları dönemin sonuç hesaplarına kaydedilmesi gerekir. 
Vadeli işlem sözleşmelerinin muhasebeleştirilmesinde öncelikle sözleşme tutarı, sözleşmeye taraf olanların varlık veya kaynaklarında herhangi bir artış veya azalışa yol açmadığından sözleşmenin yapıldığı tarihte nazım hesaplara kaydedilerek sözleşme sona erene kadar nazım hesaplarda izlenmesi gerekir (Örten ve Örten,2001:185; Birgili ve Karaca, 2005:113).

Vadeli işlem sözleşmelerinde, sözleşmeye taraf olunduğu anda merkezi takas kuruluşu olan Takasbank'a bir başlangıç teminatının ödenmesi gerekir. Literatüre bakıldığında türev ürünlerin muhasebeleştirilmesi ile ilgili bazı çalışmalarda başlangıç teminatı tutarının 113 Türev Finansal Varlıklar (Okudan, 2009:69), 116 Türev Finansal Varlıklar (Ocakoğlu,2013:57; Dızman, 2014:25) hesaplarında izlendiği görülmektedir. Vadeli işlem sözleşmelerinde taraflar başlangıç teminatı tutarlarını sözleşme sonunda geri aldıkları için teminat tutarlarının sözleşme süresi boyunca "126 Verilen Depozito Ve Teminatlar Hesabı"nda izlenmesi daha uygun olacaktır. Sözleşmenin, süresi içinde borsa tarafından ilan edilen günlük uzlaşma fiyatı ile değerlenmesi sonucu ortaya çıkan kar veya zararlar bir taraf için gider, diğer taraf için ise gelir niteliğini taşıyacağından, bu tutarların sözleşmenin yapıldığı dönemin sonuç hesaplarına aktarılması gerekir.

\section{5. ÖRNEK UYGULAMA}

Örnek uygulamada önce uzun pozisyon alan yatırımcı açısından sonrada kısa pozisyon alan yatırımcı açısından yapılması gereken muhasebe kayıtlarına yer verilecektir.

1-Bir yatırımcının 25.02.2016 tarihinde VİOP'dan F_XAUTRYM0216SO kodlu gram altın vadeli işlem sözleşmesinden spekülatif amaçla 114,88TL fiyatla 100 adet satın alarak uzun pozisyon aldığını varsayalım. Söz konusu sözleşmenin büyüklüğü 1 gram altından oluşmaktadır. Yatırımcının ilgili sözleşmede pozisyon alabilmek için yatırması gereken başlangıç teminatı sözleşme başına 8TL'dir. Buna göre yatırılması gereken başlangıç teminat tutar1 800TL'dir ( $8 * 100)$. Sürdürme teminatı ise 600TL $\left(800^{*} 0,75\right)$ olarak belirlenmiştir.

-Altın vadeli işlem sözleşmesinin nazım hesaplara kaydl;

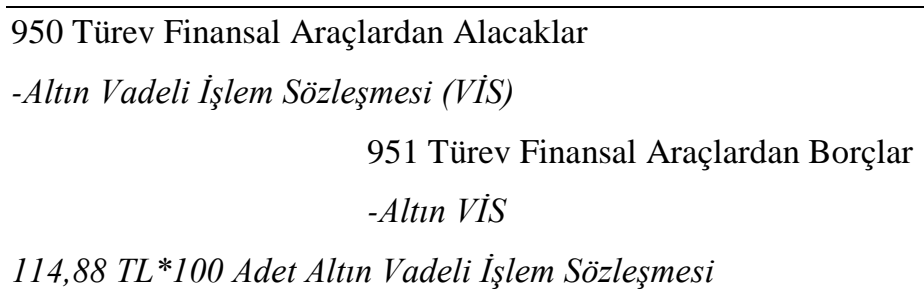

$11.488,00$

$11.488,00$ 
-Altın vadeli işlem sözleşmesi başlangıç teminatının Takasbank'a yatırılması;

126 Verilen Depozito ve Teminatları
126.0X Altın VISS Başlangıç Teminatı
102 Bankalar
Takasbank'a VIS başlangıç teminatının yatırılması

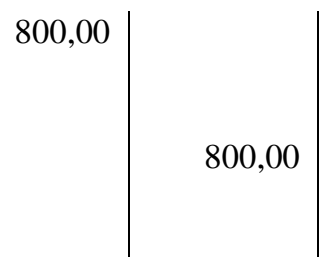

Seans sonunda sözleşmenin ilgili tarihte günlük uzlaşma fiyatı borsa tarafindan 118,63TL olarak ilan edilmiştir. Bu durumda yatırımcı uzun pozisyon aldığı için sözleşme fiyatının yükselmesi nedeniyle kar etmektedir. Yukarıdaki eşitlik kullanılarak yatırımcının günlük hesaplaşmalar sonucunda geçici karı, 375,00TL ((118,63-114,88)*1*100) olarak hesaplanmaktadır.

-Altın vadeli işlem sözleşmesi değerleme artışının kaydl;

126 Verilen Depozito ve Teminatları

126.0X Altın VIS Başlangıç Teminatı

649 Diğer Olağan Gelir ve Karlar

649.0X Altın VIS Değer Artış Karl

Altın VIS değerleme artışı geliri kaydı $(118,63-114,88) * 100$ adet

Başlangıç teminatı değerine göre oluşan fark 375,00 TL takas odası tarafından teminat hesabına eklenmektedir. Yatırımcılar futures işlemlerde yapılan günlük değerleme sonucunda teminat hesabı bakiyelerinde artış olduğunda, teminat hesaplarının başlangıç teminatı seviyesini aşan kısmını vade sonunu beklemeden hemen çekip kullanabilirler.

26.02.2016 tarihinde günlük uzlaşma fiyatının 115,95TL olarak belirlenmiştir. Sözleşme fiyatının düşmesi nedeniyle yatırımcı için zarar söz konusu olmakta ve geçici zarar tutar1 -268,00TL $((115,95-118,63) * 1 * 100)$ olarak hesaplanmaktadır.

-Altın vadeli işlem sözleşmesi değerleme azallşııın kaydl;

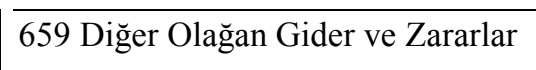

126 Verilen Depozito ve Teminatlar

126.0X Altın VíS Başlangıç Teminatı

Altın ViS değer azalışının zarar kaydı $(115,95-118,63) * 100$ adet

Yatırımcının zarar etmesi nedeniyle başlangıç teminatı sürdürme teminatının altına gerilemiş ve 532,00TL (800,00-268,00) seviyesine düşmüştür. Bu durumda teminat 
çağrısında bulunulmakta ve yatırımcının hesabına 268,00 TL yatırarak, hesap bakiyesini başlangıç teminat tutarı seviyesine çekmesi istenmektedir.

-Altın vadeli işlem sözleşmesi sürdürme teminatının tamamlanması kaydı;

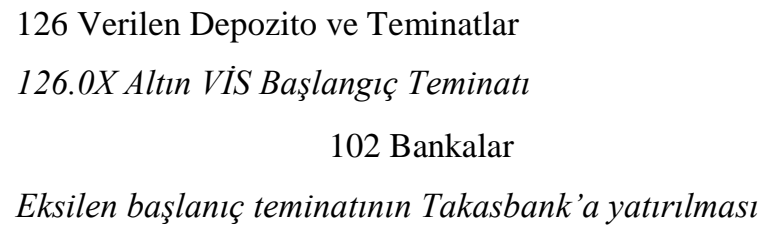

Söz konusu altın vadeli işlem sözleşmelerinde vade, şubat ayının son iş günü olan 29.02.2016 tarihidir. İlgili tarihte vade sonu uzlaşma fiyatı 117,68 olarak ilan edilmiştir. Bu durumda yatırımcının geçici karı, 173,00TL $((117,68-115,95) * 1 * 100)$ olarak hesaplanmaktadır. Yatırımcının pozisyonunu vade sonunda kapatması durumunda kesinleşen toplam kar 280,00TL'dir $(375,00-268,00+173,00)$ yada $(117,68-114,88) * 1 * 100)$.

-Altın vadeli işlem sözleşmesi vade sonunda yapılacak kayıtlar;

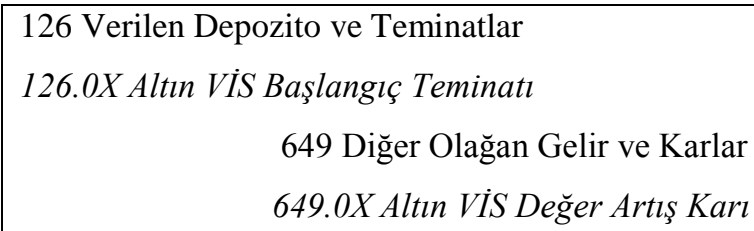

-Altın vadeli işlem sözleşmesi nazım hesapların kapatılması;

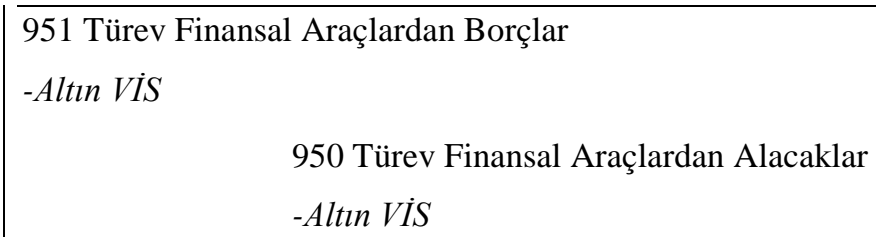

2-Yatırımcinın uzun pozisyon yerine 25.02.2016 tarihinde F_XAUTRYM0216SO kodlu gram altın vadeli işlem sözleşmesinde 114,88TL fiyatla 100 adet kısa pozisyon aldığını 
varsayalım. Başlangıç ve sürdürme teminatları uzun pozisyonda olduğu gibi sırasıyla $800 \mathrm{TL}$ ve $600 \mathrm{TL}$ olarak belirlenmiştir.

-Altın vadeli işlem sözleşmesinin nazım hesaplara kaydl; Altın vadeli işlem sözleşmesinde kısa pozisyon alan yatırımcı sözkonusu sözleşme büyüklüğü olan 11.488,00TL'yi nazım hesaplarda izleyecektir. Sözleşmenin nazım hesaplarda izlenmesi kaydı yukarıdaki örnekte verildiği için tekrar verilmemiştir.

-Altın vadeli işlem sözleşmesi başlangıç teminatının Takasbank'a yatırılması;
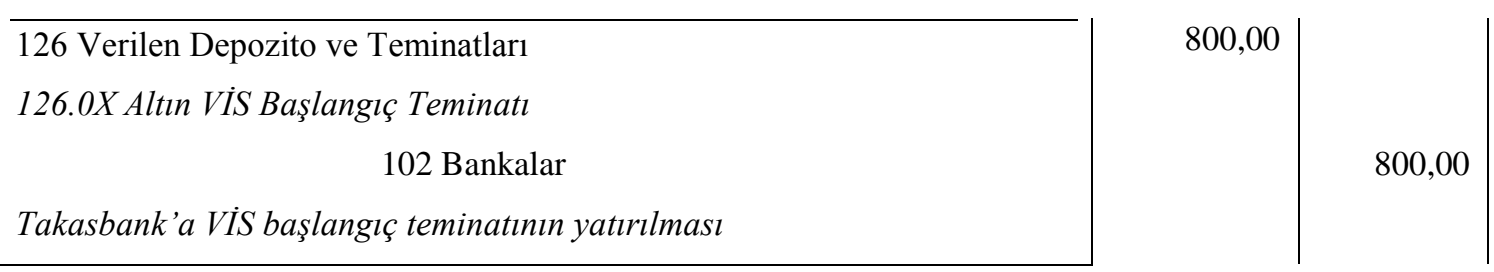

Sözleşmenin ilgili tarihteki günlük uzlaşma fiyatı borsa tarafindan 118,63TL olarak ilan edilmiştir. Bu durumda yatırımcı kısa pozisyon aldığı için sözleşme fiyatının yükselmesi nedeniyle zarar etmektedir. Yukarıdaki eşitlik kullanılarak yatırımcının günlük hesaplaşmalar sonucunda geçici zararı, -375,00TL $((114,88-118,63) * 1 * 100)$ olarak hesaplanmaktadır.

-Altın vadeli işlem sözleşmesi değerleme azallşııın kaydl;

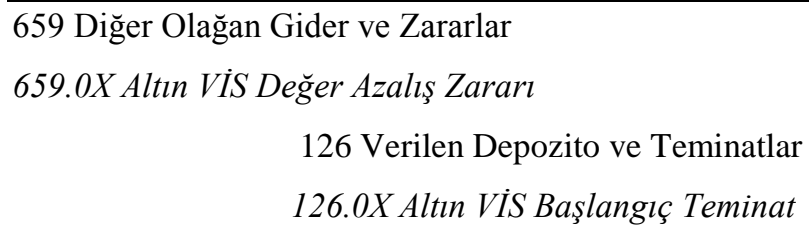

Yatırımcının zarar etmesi nedeniyle başlangıç teminatı sürdürme teminatının altına gerilemiş ve 425,00TL (800,00-375,00) seviyesine düşmüştür. Bu durumda teminat çağrısında bulunulmakta ve yatırımcının hesabına $375,00 \mathrm{TL}$ yatırarak, hesap bakiyesini başlangıç teminat tutarı seviyesine çekmesi istenmektedir.

-Zarar nedeniyle azalan başlangıç teminatının tamamlanması;

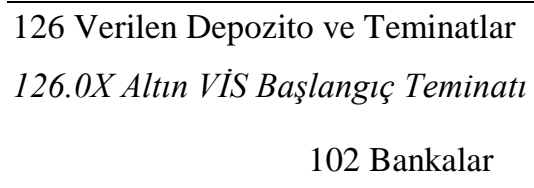


26.02.2016 tarihinde günlük uzlaşma fiyatının 115,95TL olarak belirlenmiştir. Sözleşme fiyatının düşmesi nedeniyle yatırımcı için kar söz konusu olmakta ve geçici kar tutar1 268,00TL $((118,63-115,95) * 1 * 100)$ olarak hesaplanmaktadır.

-Altın vadeli işlem sözleşmesi değerleme artışının kaydı;

126 Verilen Depozito ve Teminatları

126.0X Altın VIS Başlangıç Teminatı

649 Diğer Olağan Gelir ve Karlar

649.0X Altın VISS Değer Artış Karl

Altın VIS değerleme artışı gelir kaydı (118,63-115,95)*100

Söz konusu altın vadeli işlem sözleşmelerinde vade, şubat ayının son iş günü olan 29.02.2016 tarihidir. İlgili tarihte vade sonu uzlaşma fiyat1 117,68 olarak ilan edilmiştir. $\mathrm{Bu}$ durumda yatırımcının geçici zararı, -173,00TL $((115,95-117,68) * 1 * 100)$ olarak hesaplanmaktadır. Yatırımcının pozisyonunu vade sonunda kapatması durumunda kesinleşen toplam zarar -280,00TL’'dir $(-375,00+268,00-173,00)$ yada $(114,88-117,68) * 1 * 100)$.

-Altın vadeli işlem sözleşmesi vade sonunda yapılacak kayıtlar;

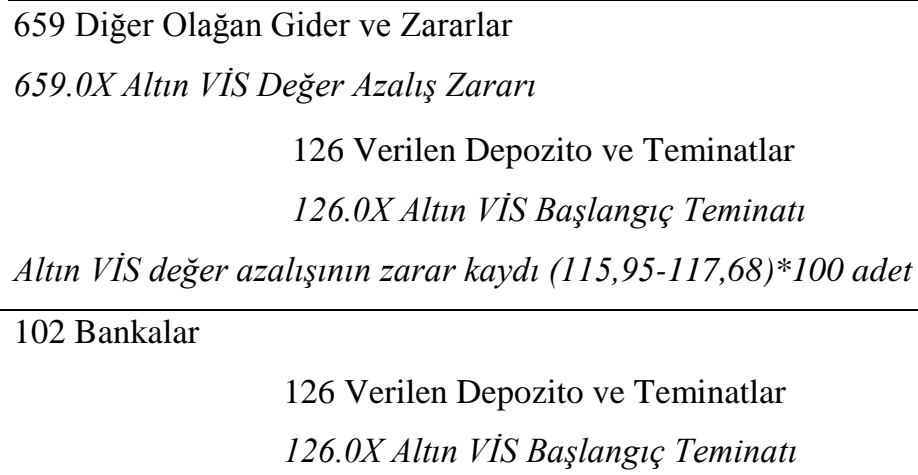

126 Verilen Depozito ve Teminatlar

126.0X Altın VIS Başlangıç Teminatı

Altın VíS değer azalışının zarar kaydı $(115,95-117,68) * 100$ adet 102 Bankalar

126 Verilen Depozito ve Teminatlar

126.0X Altın ViS Başlangıç Teminatı

Altın VİS Başlangıç teminatının tahsili

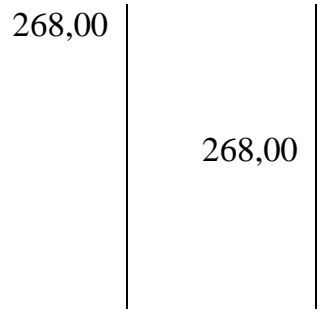


emtialar üzerine de düzenlenebilmektedir. Ülkemizde, BİST bünyesinde faaliyet gösteren VİOP’ta vadeli sözleşmeleri işlem görmeye başlamıştır. Bu piyasada işlem gören sözleşmelerden biri de altın vadeli işlem sözleşmeleridir. Altın fiyatlarındaki oynaklık altın yatırımcısının ve işletmelerin piyasa riskine maruz kalmasına neden olmaktadır. Altın fiyatlarındaki oynaklıktan spekülatif olarak yararlanmak veya maruz kalınan riski yönetmek amacıyla yatırımcılar ve işletmeler altın vadeli işlem sözleşmelerine taraf olabilmektedir.

Bir vadeli işlem sözleşmesinde uzun pozisyon alan yatırımcı, sözleşmenin piyasa fiyatının artması durumunda kar ederken, sözleşme fiyatının düşmesi durumunda zarar etmektedir. Kısa pozisyon alan bir yatırımcı ise sözleşme fiyatının artması durumunda zarar, azalması durumunda ise kar etmektedir.

Türev finansal araçların muhasebeleştirilmesi ve finansal tablolarda raporlanması ile ilgili düzenlemeler getiren TMS 39 Finansal Araçlar: Muhasebeleştirme ve Ölçme standardında türev ürünler, gerçeğe uygun değer farkı kar veya zarara yansıtılan finansal varlıklar arasında sayılmıştır. Standarda göre; gerçeğe uygun değer farkı kar veya zarara yansitılan finansal varlıklar ilk kez ve sonraki dönemlerde muhasebeleştirilirken gerçeğe uygun değer ile ölçülmelidir ve ortaya çıkan kazanç veya kayıplar da ilgili dönemin sonuç hesaplarına aktarılmalıdır.

\section{KAYNAKLAR}

Bouchentouf, Amine (2007), Commodities for dummies, Wiley Publishing, Canada.

Birgili, Erhan - Karaca, Nevran ve Akyel, Nermin (2005), "Futures Sözleşmeler ve Muhasebeleştirilmesi”, Muhasebe ve Finans Dergisi, Sayı 26 (Nisan), ss.109-119.

Ceylan, Ali - Korkmaz, Turhan (2008), İşletmelerde finansal yönetim, 4. Baskı, Ekin Basım Yayın, Bursa.

Chambers, Nurgül (2012), Türev Piyasalar, Beta Basım Yayım Dağıtım A.Ş., İstanbul.

Çonkar, Kemalettin - Ata, H.Ali (2002), "Riskten korunma aracı olarak türev ürünlerin gelişmiş ülkeler ve Türkiye'de kullanımı”. Afyon Kocatepe Üniversitesi İiBF Dergisi, 4(2), ss.1-17.

Dızman, Şakir (2014), “Türev Finansal Ürünlerin; Türkiye Muhasebe Standartları (TMS), Türkiye Finansal Raporlama Standartları (TFRS) Ve Yeni Hesap Planı Taslağı Kapsamında Muhasebeleştirilmesi”. Erzurum Üniversitesi Sosyal Bilimler Enstitüsü Dergisi, 7(1), ss.17-30.

Doğukanl, Hatice (2008), Uluslararası Finans, Karahan Kitapevi, Adana. 
Frush, Scott (2008), Commodities demystified, 1. Edition, McGraww Hill, USA.

Hull, John. C. (2012), Options, futures and other derivative securities, 9.Edition, Pearson Inc., England.

Karatepe, Yalçın (2000), Türev piyasaları, A.Ü. Siyasal Bilgiler Fakültesi Yayını, Ankara.

Ocakoğlu, Orçun (2013), “Türev Ürünlerin Muhasebeleştirilmesi”, Mali Çözüm, Sayı,120 (Kasım-Aralık), ss.49-63.

Okudan, Fahrettin (2009), “TMS 39’a Göre Hisse Senedi Endeks Vadeli İşlem Sözleşmelerinin Muhasebeleştirilmesi: VOB Uygulaması”, Mali Çözüm, Sayı,95 (Eylül-Ekim), ss.57-80.

Örten, Remzi - Örten, İpek (2001), Türev Finansal Araçlar ve Muhasebe Uygulamaları, Gazi Kitapevi, Ankara.

Vadeli İşlem ve Opsiyon Borsası (2005). VOB Teminatlandırma ve Diğer Risk Yönetimi Esaslar1. http://www.vob.org.tr/VOBPortalTur/ProcedureTree/2005-6.pdf. (16.05.2016).

Vadeli İşlem ve Opsiyon Borsası (2006). VOB türev araçlar lisanslama rehberi.

http://www.vob.org.tr/VOBPortalTur/EduDocs/Turev\%20Araclar\%20Lisansla ma\%20K\%C4\%B1lavuzu-Mart_2006.pdf. ( 11.05.2016.)

http://www.borsaistanbul.com/sss/vadeli-islem-ve-opsiyon-piyasasi-viop (11.05.2016). 
